\title{
EMPLOYEE PERCEPTIONS OF THE MANAGEMENT OF CULTURAL DIVERSITY AND WORKPLACE TRANSFORMATION
}

Authors:

Pascal S. Zulu ${ }^{1}$

Sanjana B. Parumasur ${ }^{2}$

\section{Affiliations:}

${ }^{1}$ Human Rights Council of South Africa, South Africa

${ }^{2}$ School of Management, University of KwaZuluNatal, South Africa

Correspondence to: Sanjana B. Parumasur

e-mail:

brijballs@ukzn.ac.za

Postal address:

Private Bag X54001,

Durban, 4000, South

Africa

\section{Keywords:}

cultural diversity; change management in the workplace; South African Transformation Agenda; Employment Equity Act, No. 55 of 1998; perception of employees

Dates:

Received: 07 Apr. 2008

Accepted: 27 Mar. 2009

Published: 15 May 2009

How to cite this article: Zulu, P.S., \& Parumasur, S.B. (2009). Employee perceptions of the management of cultural diversity and workplace transformation. $S A$ Journal of Industrial Psychology/SA Tydskrif vir Bedryfsielkunde, 35(1), Art. \#426, 9 pages. DOI: 10.4102/sajip.v35i1.426

This article is available at: http://www.sajip.co.za

(C) 2009. The Authors. Licensee: OpenJournals Publishing. This work is licensed under the Creative Commons Attribution License.

\section{ABSTRACT}

This study assesses managerial perceptions of the management of cultural diversity and workplace transformation in three production companies in Gauteng. A sample comprising 668 employees was drawn from a population of 1259 (53\% response rate) using simple random sampling and data were collected through self-developed questionnaires and personal interviews. Data were analysed using descriptive and inferential statistics. The results indicate that whilst the South African Transformation (SAT) Agenda has propelled change in the political and economic spheres, similar developments have not been realised in the South African labour market. Hence, based on the findings, recommendations are made to enhance the management of cultural diversity and workplace transformation, and the need for urgent government intervention, through legislative amendments, is emphasised.

\section{INTRODUCTION}

The legacy of apartheid and the colonial conquest has conferred on South Africans the dubious status of being a society with one of the highest levels of inequality in the world. According to Bendix (1996), the new democratically elected government, led by the African National Congress (ANC), had to place poverty and inequality in South Africa at the top of its priorities. These identified factors were deeply disturbing phenomena that needed to be addressed, but racial, gender, religious and cultural discrimination in the workplace clearly exacerbated these problems and the government was duty-bound to redress the wrongs that had been done. However, what was not clear was the nature of the route the government was to take to remedy the situation, including labour market discrimination, that is, the inferior treatment of some employees as a result of factors unrelated to the labour market, such as gender and race (Barker, 1995). The Schenfelter (1973) approach, cited in Zulu (2001), suggested several avenues through which the South African government might have addressed the problem of discrimination in particular and transformation in general in the workplace. One general policy was to achieve a tight labour market through the use of appropriate monetary and fiscal policies. A second general policy was to improve the education and training opportunities of those who had been discriminated against (Schenfelter, cited in Zulu, 2001). The third and most obvious means of dealing with discrimination was through direct government intervention.

According to Human (1993), there were two questions relating to the nature of government intervention in eradicating inequalities in the labour market that many organisations were asking, namely 'Will affirmative action legislation be passed?' and 'What form will that legislation take?' The answer to the former was obvious as many major players in the South African context, namely the ANC, the Pan African Congress (PAC) and certain affiliates of the Congress of South African Trade Unions (Cosatu), made statements of supporting the principle of legislation relating to affirmative action in employment and contracting, in particular. All the new labour legislation in South Africa was basically aimed at correcting the historical injustices perpetuated against black people, Indians and coloured people. It was a commitment to move away from a society built on discrimination and inequality towards a nonracial, democratic society based on justice and equality.

This research focuses on this latter aspect of policy since the direct government intervention to redress the inequalities of the past through labour legislation has been a burning issue; hence, the performance of some of the acts requires scrutiny. Attention, however, will be given to the role that South African companies have played in achieving the ultimate objective of the South African Transformation (SAT) Agenda. The big question was whether the new labour legislation took the right approach in seeking to meet these legitimate concerns; hence, there was a large degree of divergence in the intellectual responses to some of the acts.

Business transformation in the South African context had extremely broad connotations. There were those who were critical and objective towards the whole process of transformation. They believed that transformation was the appropriate programme that would ensure social and economic mobility for the historically disadvantaged population groups. They viewed it as a process whereby the inequalities of the past would be corrected. While others were defensive regarding the approach, most opposition political parties and other business leaders saw the process of business transformation as a threat to the independence of the labour market. Clearly, a common view on the process was needed in order to ensure economic development and job opportunities for all. Otherwise, further division on this issue would have created an unfriendly environment and eventually forced domestic companies to close down and foreign companies to terminate their commitment to invest in South Africa.

Some political parties, trade unions and academics also raised concerns with regard to the beneficiaries of the transformation. It must be noted, however, that a blanket approach could be misleading because not all black people have been discriminated against. Hence, the question is how far the SAT Agenda should go to accommodate foreign black people who were not necessarily previously disadvantaged and whose cultural and religious practices are not necessarily South African. Furthermore, there is a 
great deal of scepticism regarding the beneficiaries of business transformation in South Africa. According to Terblanche (2002, p. 135), the laws have benefited 'only the aspirant African petit bourgeois' who already have jobs and are trade union members. Hence, affirmative action and the Employment Equity Act, No. 55 of 1998 benefit mainly the rising black middle class and effectively intensify the inherited class inequality in South African society (Alexander, 2006), thereby undermining the very concept of equality (Wilken, 2003). Clearly, there is limited, if any, opportunity for the poorest and most disadvantaged segment of the population, that is, the unemployed who constitute more than $40 \%$ of the population and are unskilled, to benefit from the act in terms of employment. Evidently, business transformation has not yet benefited the majority of South Africans as millions of Cosatu members live with the truth of rising unemployment, retrenchment and job losses every day (Cosatu Policy Unit Industrial Strategy Handbook, 2002). Cosatu argues that the state should be seen at the forefront, leading the process of business transformation in South Africa. The government maintains that the high degree of reluctance on the part of corporate business, in particular, to transform so as to address the legacy of the past compels the state to ensure that transformation does take place. According to the Employment Equity Bill (1998), after South African transition to a democratic state, the economy of the country remains largely in the hands of those privileged by apartheid with little participation from the African people. The marketplace has barely begun to be deracialised. Management is, with a few exceptions, largely white and where companies claim to have made progress in correcting the historic imbalances amongst management, this apparent progress often consists of token appointments with black managers appointed into symbolic positions without real decision-making powers.

According to Ramphele (1995), the current public debates on transformation are sadly impoverished by a focus on affirmative action, which evokes emotions from both sides of the divide. Business transformation is not about affirmative action. Affirmative action to Ramphele (1995) is a concept imported from the United States of America where it may have had a place. However, the question is whether it has a place in South Africa and if so, what its appropriate place is. There were two main differences between the local social conditions and those of the USA. Firstly, the USA had a majority white population, which in the politics of the 1960s was expected to affirm a minority black population. Secondly, there was no questioning by most Americans, black or white, of the fundamental tenets of the USA's socio-economic system besides its racism. For Ramphele (1995), South African citizens faced very different challenges. South Africa had to address the needs of a majority and be committed to the fundamental transformation of social relations. South African citizens needed to look beyond affirmative action to tackle existing problems of inequality. Nevertheless, efforts were made for black people in South Africa to gain entry into positions of responsibility in a wide range of occupations that were previously dominated by white people, but that did not constitute transformation on its own. The Employment Equity Act, No. 55 of 1998 and other new labour legislation did not specifically address the important issue of cultural diversity. Central to the whole question of business transformation is the recognition of and respect for cultural differences in the workplace. Any transformation agenda that is not speaking directly to the cultural recognition of the previously disadvantaged groups will not achieve its objectives. If one looks at the perspectives of some of the role-players around the question of business transformation one sees that little, if any, attention has been paid to the extent to which intervention strategies to transform the business sector in South Africa have contributed to the transformation of business culture in terms of, among other things, language, canteens, medical aid, dress code and social events arranged for staff.

The manner in which business transformation has been interpreted by many has been largely based on, among other things, the employment rate, skills development, promotions, income inequalities and corporate citizenship. According to Thomas and Robertshaw (1999), transformation has become a buzzword in the South African lexicon. Transformation, as it relates to the internal environment of companies in South Africa, is seldom viewed as a process for developing and maintaining a work environment in which everyone can be developed to his or her full potential and be allowed to contribute fully to the life of the company and its objectives. This, according to Thomas and Robertshaw (1999), requires that work environments be created free of unfair discrimination and reflective of the demographic realities of all the people of the country, thereby making cultural diversity within the workplace a norm and an economic necessity (Richard, McMillan-Capehart, Chadwick \& Dwyer, 2003). There is no doubt that a country such as South Africa, with a culturally heterogeneous population, must consider whether employees from different cultural groups are represented in the workforce and the level in the hierarchy at which they are working. Unfortunately the reality of business in South Africa today is that at the heart of many companies' problems lies the complex issue of cultural diversity. Different cultural and religious groups are encouraged to participate and be employed through government legislation, such as the Employment Equity Act, No. 55 of 1998, the Labour Relations Act, No. 66 of 1995 and the Basic Conditions of Employment Act, No. 75 of 1997 but clearly that is not enough. Employing more African people, coloured people, Indians and women will not constitute transformation of business on its own. The success of business transformation should never be measured only by the numbers but by the extent to which cultural values, particularly African culture, are being recognised and promoted to ensure that the organisational culture reflects diversity of experience and orientation. In this way, all employees operate in an environment that enables everybody to be competent and effective. Placing previously disadvantaged groups into positions where working conditions do not accommodate the operation of diverse cultural groups is disastrous. Without multicultural change, the principles of the act are bound to frustrate the same Africans they are intended to benefit.

A more suitable model for managing a culturally diverse workforce needs to be successfully developed. This is an aspect to which this research will have to pay more attention so as to establish how far corporate business in South Africa has gone to Africanise its policies, practices and, in particular, its management style. Issues such as language and traditional practices will be assessed in order to establish how these issues could be dealt with by existing company policies. The effective management of a culturally diverse workforce can mean changes to the working environment, including a variety of amendments to current rules and regulations. It also implies the sharing of power and decision making. Often individuals will throw up barriers to the changes required by saying that they 'treat everyone alike'. However, this research moves from treating everyone alike towards identifying a more suitable model for how to manage a culturally diverse workforce successfully and would support Kane-Berman's (2004) view that the SAT Agenda requires alternatives and not consensus.

Therefore, this study aims to establish the extent to which business transformation in South Africa has taken place, particularly in addressing the management of cultural diversity in the workplace. In this regard, attention is given to the following:

- Systems and structures in place to ensure the effective management of cultural diversity

- The level of understanding of all stakeholders with regard to the management of cultural diversity issues

- The level of understanding of the impact of workplace transformation programmes on company productivity

- The relationship between the SAT Agenda and workplace transformation 
TABLE 1

Validity: Factor analysis (rotated component matrix)

\begin{tabular}{|c|c|c|c|c|c|c|}
\hline \multirow[t]{2}{*}{ ITEM } & \multicolumn{5}{|c|}{ COMPONENT } & \multirow[b]{2}{*}{6} \\
\hline & 1 & 2 & 3 & 4 & 5 & \\
\hline Q2.43 & 0.748 & 0.087 & 0.152 & 0.081 & 0.068 & 0.014 \\
\hline Q2.42 & 0.736 & 0.198 & 0.196 & 0.135 & -0.067 & 0.071 \\
\hline Q2.44 & 0.678 & 0.091 & 0.069 & 0.055 & 0.028 & 0.096 \\
\hline Q2.23 & 0.531 & 0.045 & 0.178 & 0.045 & 0.242 & -0.206 \\
\hline Q2.38 & 0.452 & 0.083 & 0.431 & 0.030 & 0.145 & 0.197 \\
\hline Q2.41 & 0.445 & 0.329 & 0.319 & 0.193 & -0.018 & 0.123 \\
\hline Q2.14 & 0.438 & 0.204 & 0.033 & -0.043 & 0.240 & 0.227 \\
\hline Q2.25 & 0.413 & 0.235 & 0.240 & 0.081 & 0.344 & 0.191 \\
\hline Q2.28 & 0.371 & 0.073 & 0.294 & -0.132 & 0.296 & 0.212 \\
\hline Q2.29 & 0.158 & 0.667 & 0.113 & 0.217 & 0.022 & 0.209 \\
\hline Q2.11 & 0.319 & 0.649 & 0.007 & 0.170 & 0.139 & 0.104 \\
\hline Q2.10 & 0.113 & 0.638 & 0.091 & 0.254 & 0.126 & 0.214 \\
\hline Q2.20 & 0.188 & 0.611 & 0.293 & 0.142 & 0.162 & -0.013 \\
\hline Q2.19 & 0.013 & 0.599 & 0.333 & 0.232 & 0.010 & 0.099 \\
\hline Q2.12 & 0.473 & 0.507 & 0.027 & -0.009 & 0.245 & 0.009 \\
\hline Q2.13 & 0.421 & 0.421 & -0.017 & 0.052 & 0.378 & -0.112 \\
\hline Q2.16 & 0.090 & 0.379 & 0.137 & -0.032 & 0.303 & 0.298 \\
\hline Q2.24 & 0.276 & 0.307 & 0.203 & 0.114 & 0.327 & 0.274 \\
\hline Q2.34 & 0.184 & 0.070 & 0.611 & 0.109 & 0.316 & -0.042 \\
\hline Q2.29 & -0.026 & 0.290 & 0.598 & 0.076 & -0.186 & 0.080 \\
\hline Q2.33 & 0.165 & -0.132 & 0.592 & 0.072 & 0.178 & 0.057 \\
\hline Q2.30 & 0.001 & 0.218 & 0.551 & -0.041 & -0.004 & 0.261 \\
\hline Q2.31 & 0.177 & 0.260 & 0.549 & 0.248 & 0.188 & -0.072 \\
\hline Q2.36 & 0.058 & -0.015 & 0.543 & -0.158 & -0.093 & 0.264 \\
\hline Q2.37 & 0.373 & 0.150 & 0.519 & 0.068 & 0.043 & 0.109 \\
\hline Q2.35 & 0.308 & 0.060 & 0.474 & 0.021 & 0.376 & -0.001 \\
\hline Q2.39 & 0.191 & 0.200 & 0.450 & 0.086 & 0.271 & 0.128 \\
\hline Q2.40 & 0.101 & 0.179 & 0.370 & 0.082 & -0.304 & 0.346 \\
\hline Q2.2 & 0.053 & 0.310 & 0.102 & 0.774 & 0.012 & 0.134 \\
\hline Q2.3 & 0.163 & 0.227 & 0.027 & 0.696 & 0.175 & 0.040 \\
\hline Q2.1 & -0.170 & 0.327 & 0.152 & 0.685 & -0.033 & 0.185 \\
\hline Q2.4 & 0.438 & 0.033 & 0.018 & 0.551 & 0.218 & -0.062 \\
\hline Q2.21 & 0.188 & 0.329 & 0.184 & 0.093 & 0.543 & -0.068 \\
\hline Q2.7 & 0.021 & 0.184 & 0.051 & 0.218 & 0.538 & 0.319 \\
\hline Q2.5 & 0.088 & 0.010 & -0.019 & 0.449 & 0.518 & 0.010 \\
\hline Q2.22 & 0.411 & 0.104 & 0.214 & 0.062 & 0.426 & -0.115 \\
\hline Q2.26 & 0.307 & 0.196 & 0.217 & 0.035 & 0.386 & 0.255 \\
\hline Q2.15 & -0.091 & 0.219 & 0.130 & -0.005 & 0.283 & 0.675 \\
\hline Q2.18 & 0.016 & 0.110 & 0.113 & 0.031 & 0.025 & 0.607 \\
\hline Q2.17 & 0.132 & -0.013 & 0.150 & 0.134 & -0.035 & 0.607 \\
\hline Q2.6 & 0.234 & -0.012 & 0.014 & 0.347 & 0.319 & 0.419 \\
\hline Q2.8 & 0.084 & 0.350 & 0.017 & 0.274 & 0.353 & 0.372 \\
\hline$\%$ OF TOTAL VARIANCE & 10.53 & 9.289 & 9.145 & 6.639 & 6.563 & 6.146 \\
\hline EIGENVALUE & 4.425 & 3.901 & 3.841 & 2.788 & 2.756 & 2.581 \\
\hline
\end{tabular}

- Employee involvement in matters of transformation

- The contribution of the labour legislation to the management of cultural diversity.

\section{RESEARCH DESIGN}

\section{Research approach}

The research methodology was designed to investigate employee perceptions of the management of cultural diversity and workplace transformation by obtaining primary data, using a cross-sectional approach. In this formal, hypothesistesting study, the unit of analysis is a group of employees from whom quantitative data, using self-developed questionnaires, and qualitative data, using personal interviews (structured), were collected.

\section{Respondents}

The population for the study comprised a total of 1259 employees from three production companies (one company from the science and information industry and two companies from the food and beverage industry) in Gauteng. A sample of 668 respondents was drawn using the simple random sampling technique as this method has the least bias and offers the greatest generalisability of results. According to Sekaran (2003), the corresponding minimum sample size for a population size of 1259 is approximately 297 , thereby confirming the adequacy of the sample size of 668 . The adequacy of the sample was further determined using the Kaiser-Meyer-Olkin Measure of Sampling Adequacy (0.910) and the Bartlett's Test of Spherecity (10 552.791; $\mathrm{p}=0.00)$, which respectively indicated suitability/adequacy and significance. The results indicate that the normality and homoscedasticity preconditions are satisfied.

\section{Measuring instruments}

Data were collected using a self-developed measuring instrument that focused on the management of cultural diversity and workplace transformation. Respondents were requested to indicate their understanding, experience and perception of cultural diversity in the workplace using a five-point Likert scale ranging from strongly disagree (1) to strongly agree (5). Six key 
TABLE 2

Descriptive statistics: Key dimensions relating to the management of cultural diversity

\begin{tabular}{|c|c|c|c|c|c|}
\hline \multirow[t]{2}{*}{ DIMENSIONS } & \multirow[t]{2}{*}{ MEAN } & \multicolumn{2}{|c|}{ 95\% CONFIDENCE INTERVAL } & \multirow[t]{2}{*}{ VARIANCE } & \multirow[t]{2}{*}{ STANDARD DEVIATION } \\
\hline & & Lower bound & Upper bound & & \\
\hline Systems and structures in place & 2.771 & 2.719 & 2.822 & 0.464 & 0.681 \\
\hline Understanding of stakeholders & 2.839 & 2.703 & 2.885 & 0.368 & 0.607 \\
\hline Impact on productivity & 2.402 & 2.908 & 2.414 & 0.023 & 0.151 \\
\hline SAT Agenda & 2.586 & 2.568 & 2.604 & 0.058 & 0.241 \\
\hline Employee involvement & 2.361 & 2.346 & 2.375 & 0.037 & 0.191 \\
\hline Employee equity legislation & 2.493 & 2.480 & 2.507 & 0.032 & 0.179 \\
\hline
\end{tabular}

TABLE 3

Intercorrelations: Key dimensions of the study relating to the issues of the management of cultural diversity $(n=668)$

\begin{tabular}{|c|c|c|c|c|c|c|c|}
\hline DIMENSION & & $\begin{array}{l}\text { SYSTEMS AND } \\
\text { STRUCTURES IN } \\
\text { PLACE }\end{array}$ & $\begin{array}{l}\text { UNDERSTANDING OF } \\
\text { STAKEHOLDERS }\end{array}$ & $\begin{array}{c}\text { IMPACT ON } \\
\text { PRODUCTIVITY }\end{array}$ & $\begin{array}{c}\text { SAT } \\
\text { AGENDA }\end{array}$ & $\begin{array}{l}\text { EMPLOYEE } \\
\text { INVOLVEMENT }\end{array}$ & $\begin{array}{c}\text { EMPLOYEE } \\
\text { EQUITY } \\
\text { LEGISLATION }\end{array}$ \\
\hline Systems and structures in place & $\begin{array}{l}\mathrm{r} \\
\mathrm{p}\end{array}$ & 1 & & & & & \\
\hline Understanding of stakeholders & $\begin{array}{l}\mathrm{r} \\
\mathrm{p}\end{array}$ & $\begin{array}{r}0.704 \\
0.000^{*}\end{array}$ & 1 & & & & \\
\hline Impact on productivity & $\begin{array}{l}\mathrm{r} \\
\mathrm{p}\end{array}$ & $\begin{array}{r}0.523 \\
0.000^{*}\end{array}$ & $\begin{array}{r}0.481 \\
0.000^{*}\end{array}$ & 1 & & & \\
\hline SAT Agenda & $\begin{array}{l}r \\
p\end{array}$ & $\begin{array}{r}0.360 \\
0.000^{*}\end{array}$ & $\begin{array}{l}0.202 \\
0.000^{*}\end{array}$ & $\begin{array}{r}0.164 \\
0.000^{*}\end{array}$ & 1 & & \\
\hline Employee involvement & $\begin{array}{l}r \\
p\end{array}$ & $\begin{array}{l}0.437 \\
0.000^{*}\end{array}$ & $\begin{array}{r}0.299 \\
0.000^{*}\end{array}$ & $\begin{array}{r}0.212 \\
0.000^{*}\end{array}$ & $\begin{array}{r}0.310 \\
0.000^{*}\end{array}$ & 1 & \\
\hline Employee equity legislation & $\begin{array}{l}\mathrm{r} \\
\mathrm{p}\end{array}$ & $\begin{array}{r}0.446 \\
0.000^{*}\end{array}$ & $\begin{array}{r}0.464 \\
0.000^{*}\end{array}$ & $\begin{array}{l}0.367 \\
0.000^{*}\end{array}$ & $\begin{array}{r}0.279 \\
0.000^{*}\end{array}$ & $\begin{array}{r}0.362 \\
0.000^{*}\end{array}$ & 1 \\
\hline
\end{tabular}

${ }^{*} p<0.01$

dimensions relating to the management of cultural diversity and workplace transformation were assessed:

- Systems and structures put in place to ensure the effective management of cultural diversity.

- Understanding of stakeholders (role-players) of the management of cultural diversity issues.

- Impact of workplace transformation programmes on company productivity.

- Relationship between the SAT Agenda and workplace transformation. The objective was to establish whether the socio-economic and political achievements by South Africa as a country are reflected in the day-to-day operations in the workplace.

- Employee involvement in matters of transformation.

- The contribution of the Employment Equity Act, No. 55 of 1998 to the management of cultural diversity. The objective was to understand the limitations, if any, of the existing Employment Equity Act, No. 55 of 1998 in promoting the management of cultural diversity.

In addition, qualitative data were collected using interviews assessing the same dimensions that were measured in the questionnaire. Personal interviews were arranged and conducted with the group diversity manager of the food and beverage industry and the chairperson of the trade union from a company in the science and information industry and a Department of Labour official on a one-on-one basis in their offices using only the English language as medium of communication.

\section{Procedure}

In-house pretesting was done by distributing the designed questionnaire to colleagues and experts in the field to comment on the items, structure and layout of the measuring instrument. In addition, pilot testing was used to detect weaknesses in the design and instrumentation, if any, using the same protocols and procedures as those designated for the actual data collection process. Ten questionnaires were distributed to various categories of employees that reflected the demographics of those included in the main study. The pilot study confirmed, among other things, the adequacy of the items.

\section{Statistical analysis}

The validity of the questionnaire was statistically analysed using factor analysis (see Table 1). Principal component analysis was adopted using the Varimax rotation method and generated six factors with latent roots $>1$. Only items with loadings $>0.5$ were regarded as being significant and when an item was significant 
TABLE 4

Qualitative analyses of employee participation in and ratings of the issues of cultural diversity and workplace transformation (percentages)

\begin{tabular}{|c|c|c|c|c|c|}
\hline PERCEPTION/RATING & $\begin{array}{r}\text { SD } \\
1\end{array}$ & $\begin{array}{l}D \\
2\end{array}$ & $\begin{array}{r}\text { NA/ND } \\
3\end{array}$ & $\begin{array}{l}\text { A } \\
4\end{array}$ & $\begin{array}{r}\text { SA } \\
5\end{array}$ \\
\hline Transformation is the responsibility of management. & 10 & 30.6 & 32.8 & 21.2 & 5.4 \\
\hline $\begin{array}{l}\text { Employee association/business forum programmes are needed to assist companies in managing cultural } \\
\text { diversity. }\end{array}$ & 7.3 & 26.6 & 45.1 & 17.9 & 3.1 \\
\hline South African business is committed to addressing the management of cultural diversity in the workplace. & 14.3 & 20.4 & 33.6 & 25 & 6.6 \\
\hline $\begin{array}{l}\text { The company does attempt to establish systems and structures to assist previously disadvantaged groups } \\
\text { to acclimatise to company culture. }\end{array}$ & 8.3 & 27 & 35.9 & 24 & 4.8 \\
\hline The management of cultural diversity impacts positively on productivity. & 7.6 & 19.6 & 48.7 & 20.3 & 3.8 \\
\hline There is a significant relationship between the SAT Agenda and workplace transformation. & 7.9 & 25.2 & 35.3 & 26.4 & 5.2 \\
\hline Employees are involved in workplace transformation in their respective companies. & 11.9 & 21.3 & 37.6 & 21 & 8.2 \\
\hline
\end{tabular}

on two or more factors, only that with the greatest loading was considered.

Table 1 indicates that the questionnaire generated six factors relating to the impact of the management of cultural diversity on productivity; systems and structures in place; employee involvement in workplace transformation; employment equity legislation; the relationship between the SAT Agenda and workplace transformation; and understanding of stakeholders, respectively.

The reliability of the questionnaire was statistically assessed using Cronbach's coefficient alpha and indicated a very high level of internal consistency of the items (alpha $=0.923)$ and hence, a very high degree of reliability. Descriptive statistics (frequency analyses, mean analyses and standard deviations) and inferential statistics (correlations, ANOVA and post-hoc Scheffe's test) were used to analyse the results of the study.

\section{RESULTS}

Table 2 indicates the descriptive statistics (means, variance, standard deviations and critical values) for each of the management of cultural diversity dimensions.

When comparing the mean score values per variable, it is evident that their deviation from a maximum attainable score value of five reflects room for improvement. This indicates that employees perceive that companies have engaged in insufficient effort to address issues of workplace transformation. In descending level of accomplishment, based on mean values, the results indicate that employees have the most positive view of the understanding of stakeholders and the least confidence in the extent of employee involvement (frequency analyses are also reflected):

- Understanding of stakeholders regarding the management of cultural diversity (mean $=2.839$ ). The frequency analyses reflect that $37.4 \%$ of all respondents agreed with the view that only the English language is used for the purposes of communication. Also, $39.5 \%$ of the respondents agreed that only medical certificates from recognised practitioners are acknowledged as proof of illness.

- Systems and structures in place to ensure the effective management of cultural diversity and full participation of employees $($ mean $=2.771)$. A significant segment of respondents were neutral in this regard (17.7\%).

- The relationship between the SAT Agenda and workplace transformation $($ mean $=2.586)$. It was found that $38.2 \%$ of the subjects were neutral on whether all employees are represented in their company's Employment Equity Forum.
- Employment equity legislation contribution towards the recognition of cultural diversity in companies (mean = 2.493). It was found that $54 \%$ of the respondents were neutral on this issue. In addition, $39.7 \%$ were neutral on whether the majority of senior/strategic positions are in the hands of historically disadvantaged groups.

- Impact of workplace transformation programmes on company productivity (mean $=2.402)$. It was found that $47.9 \%$ of the respondents were neutral on their responses on whether the management of cultural diversity positively affects the smooth running of the business.

- Employee involvement in matters of workplace transformation $($ mean $=2.361)$. The findings reflect that $42.4 \%$ of the subjects were neutral on whether all employees have been capacitated in all anti-discrimination legislation in their companies, whilst $33.7 \%$ were neutral on employee involvement in the process of managing cultural diversity.

From the aforementioned, it is clear that a large segment of the respondents was neutral on all key dimensions. This indicates that there is little or no commitment from South African companies to addressing the management of cultural diversity in the workplace or if there is any, it is certainly not being effectively communicated to the employees. The results indicate that issues of cultural diversity are not taken seriously by companies and hence, there is little understanding from South African employees of what workplace transformation should entail and what the management of cultural diversity is all about.

\section{Hypothesis 1}

Significant intercorrelations exist amongst the dimensions of the study (systems and structures in place, understanding of stakeholders, impact on productivity, SAT Agenda, employee involvement and employment equity legislation) that determine the extent to which South African companies are transforming the existing corporate culture (see Table 3 ).

Table 3 indicates that significant intercorrelations exist amongst the dimensions of the study that determine the extent to which South African companies are transforming the existing corporate culture. The fact that employees display unhappiness about and a lack of confidence in the extent to which South African companies are transforming the corporate culture (as evidenced in the descriptive statistics) and that these dimensions are significantly intercorrelated reflects that the issues regarding the management of cultural diversity individually and then compositely are largely neglected and have the potential to snowball into a serious lack of management of diversity and transformation issues. 


\section{Qualitative analyses}

Qualitative analyses of the perceptions of employees regarding their participation in and of their ratings of the issues of cultural diversity and workplace transformation were undertaken. Employees were required to reflect on who they believed was responsible for ensuring that transformation took place, their views of the involvement of employee associations and business forum programmes and the dimensions testing the objectives of the study (systems and structures in place, understanding of stakeholders, impact on productivity, SAT Agenda, employee involvement and employee equity legislation) respectively (see Table 4).

Table 4 indicates that whilst $32.8 \%$ of the respondents did not know who should be responsible for the transformation process, more employees $(40.6 \%)$ disagreed or strongly disagreed that it was the responsibility of management than those who agreed or strongly agreed $(26.6 \%)$. Only $17.9 \%$ agreed and a further $3.1 \%$ strongly agreed that employee association or business forum programmes are needed to assist companies in managing cultural diversity whilst the majority $(45.1 \%)$ remained neutral on the issue. More respondents either disagreed or strongly disagreed $(34.7 \%)$ that South African business is committed to addressing the management of cultural diversity in the workplace than the $31.6 \%$ who either agreed or strongly agreed, whilst a significant segment remained neutral (33.6\%). Similar results were obtained to the statement 'the company does attempt to establish systems and structures to assist previously disadvantaged groups to acclimatise to company culture'. Furthermore, whilst an alarming $48.7 \%$ of the employees remained neutral, $24.1 \%$ either agreed or strongly agreed that the management of cultural diversity impacts positively on productivity. In addition, less than one-third of the respondents $(31.6 \%)$ believed that there is a significant relationship between the SAT Agenda and workplace transformation. Of major concern is that one-third of the employees $(33.2 \%)$ in these organisations either disagreed or strongly disagreed that employees are involved in workplace transformation in their respective companies.

In addition, personal interviews were conducted with a government official, a management representative of the company from the food and beverage industry (those management representatives from the other two companies that were not interviewed completed interview schedules) and a trade union representative of the company from the science and information industry. During the personal interviews it was established that very few measures had been put in place to fast-track transformation programmes in all three companies identified for the study. This was attributed to a number of challenges including lack of understanding by various stakeholders, little or no commitment from top management to addressing issues of workplace transformation as well as lack of resources from companies to implement programmes that are aimed at addressing the management of cultural issues. Furthermore, it was also established that no effective systems had been put in place by the Department of Labour to identify companies and organisations that do not comply with relevant legislative requirements that are aimed at redressing previously discriminatory practices. From the interviews conducted, particularly those with management and trade union representatives, it was established that human resources policy documents had not been reviewed and amended to reflect cultural differences among employees. Specific responses from the interviewees with regard to key issues of workplace transformation were also identified.

\section{Interview with group diversity manager}

The group diversity manager (food and beverage industry) mentioned that the company had come a long way in managing issues of diversity and transformation but acknowledged that much still had to be done. A number of programmes and models have been implemented in the company without success. An American consultant was also employed to tailor-make a comprehensive management of diversity and transformation programme that was to assist the company in transforming, but this was never effectively implemented. The company has been successful, however, in its employee engagement strategy, which includes a transformation website for employees and customers, communiqués and consultative structures being in place.

In the company's five-year transformation plan from 2000 to 2005 , its aim was to achieve $60 / 40$ in terms of representation of women and race. This was not attained but learnership programmes have been instituted to enhance the development of women and previously disadvantaged race groups in order to better equip them for applications for promotion.. The group diversity manager did recognise that the company has a reasonable budget to implement transformation programmes, thereby reflecting management's willingness to transform. However, he added that staff members are operating in an intensively deadline-driven environment and hence there is very little understanding and contribution from the majority of the stakeholders. In order to accommodate different cultural groups, the company has a clear Employment Equity Plan, which compels the company to employ more black personnel. However, this is hampered by the serious lack of skilled and experienced candidates. In terms of representation on the Employment Equity Forum and the Transformation Forum, attempts are made to ensure representation but sometimes these issues are not taken seriously and incumbents feel they can always deal with issues on their own. With regard to the role of human resources policies in including programmes that enable different cultural groups to feel accommodated, the manager stated that the company has induction programmes but not mentorship programmes. Employees are trained but the manager emphasised that transformation is not just about employees but also about the company's social responsibility programmes and Black Economic Empowerment (BEE). In this regard the company has made a significant contribution as its procurement policies give preference to black firms as part of its transformation agenda. The company has never been audited on its transformation programmes but has submitted reports to top management and other statutory reports to the relevant government departments.

\section{Interview with chairperson of the trade union}

The chairperson of the trade union (science and information industry) believes that consultative structures are 'window dressing' whereby management simply informs on what it will be doing and when suggestions or proposals are made they will be considered but eventually it is management's original presentation that is implemented. Whilst the largest company in the sample has impressive transformation sites and newsletters, the chairperson believes that the emphasis of transformation is not on the workers but on who they do business with, that is, BEE. He added that whilst he has representation on employment equity forums, his role is very insignificant as they are only called on when the company has to submit its Annual Employment Equity Report. He emphasised that the majority of managers are still white and male and the criteria for promotion are not transparent. The five-year Employment Equity Plan of 60/40 women and race representation has not been met and some business units still only have white employees, for example, the highly skilled technical divisions. There are only one black woman and one white woman with two black males at the executive level. As a way forward in the SAT Agenda, the chairperson suggested as a starting point the need for proper consultation as it is a mockery to design and implement transformation programmes for the role-players when the very same employees have no proper participation in the process because the current process involves technical divisions and not support staff.

\section{Interview with Department of Labour official}

According to the official, employers who do not comply by submitting company employment equity reports are first 
advised to do so and then inspectors from provincial offices follow up by visiting such employers to establish the reasons for noncompliance. If employers still do not comply, a compliance order will be issued, giving them 60 days to comply, failing which they will be taken to the labour court. According to the official the first cycle for employment equity reports submission was in 2000 and since then the number has decreased due to, among other things, mergers of companies and insolvency. He acknowledged that the compliance by companies was 'quite good' and that the Department of Labour does not have an effective method of establishing which employers are not complying with the legislation and is still dependent on trade unions, employment equity forums and ordinary employees to inform the department on what the employers are doing in relation to employment equity legislation. However, random inspection, called 'bliss inspection', can be carried out and the employer is officially informed by the provincial offices of the visit. Thus far, according to the official of the Department of Labour, other than the new Code of Good Practice, which compels companies to reflect their employment equity principles in all human resources policies, consideration has only been given to figures and reports. No consideration is given to mentorship programmes and establishment of structures and/ or systems to ensure that all employees are working or operating in an environment that is conducive to the functioning of all employees irrespective of cultural background.

\section{DISCUSSION}

\section{Interpretation}

The results reflect that employees are of the view that issues regarding transformation and cultural diversity are not sufficiently managed.

\section{Systems and structure}

All three companies selected for the study had average mean scores (mean $=2.77$ against a maximum attainable score of five), which indicated the limited, nonexistent or ineffective systems and structures that had been put in place by these companies to advance the SAT Agenda. Clearly, without viable structures or systems such as transformation forums, mentorship programmes and human resources policies to support the integration of previously disadvantaged groups into corporate environments, no transformation effort will yield results and the effective management of cultural diversity will not be realised.

Transformation should not just be about the employment of previously disadvantaged groups but also about making sure that they are made part of the companies for which they are working. Despite an impressive picture of employment figures, Ngobeni (2006) reports an increase in job-hopping by black talent; it is evident that young talent in this country is restless and highly mobile. Job-hopping is damaging and costly to an organisation as it is expensive to recruit and train individuals only to lose them a short while later. Research by the Unilever Institute at the University of Cape Town found that a significant number of black employees (65\%) had changed jobs at least once within the past three years. This is well short of the five-year period most human resources managers would aim to retain people in their jobs. Cruz, cited in Ngobeni (2006), found that culture clash, stifling corporate cultures and hostile environments are major contributors to job-hopping. Also, empowerment and affirmative action are often coupled with an undercurrent of paternalism that tends to underestimate the talent and ability of individuals. The management of cultural diversity in South Africa has been further complicated by the large number of female employees who have entered the South African labour market. Despite their employment, companies have not accommodated them as people who have specific needs, as evidenced in the current study. According to Barbara Moses (2006:6), women are alienated from 'testosterone-fuelled corporate cultures'.
Hence, if the organisational culture is not an enabling one (Brown, cited in Ntuli, 2006), it will be a matter of time before the hired person leaves, no matter how qualified or knowledgeable. There must be successful integration of transformation programmes into human resources practices that can help to shape an appropriate and supportive workplace environment.

\section{Understanding of stakeholders/role-players}

The results of the study reflect average mean scores (mean = 2.84 against a maximum attainable score of five) and a large number of respondents were neutral on several items relating to their understanding of what workplace transformation is about and who should spearhead the process in South Africa and how this should be done. The survey results reflect little effort by these companies to prioritise issues of transformation and accommodate and take special cognisance of employee needs and cultural differences. The lack of recognition of their religious holidays and of medical certificates from traditional healers is a potential reason why employees still feel discriminated against. Respondents and trade union members expressed insufficient commitment by the business community in South Africa and a lack of leadership and poor education initiatives to lead and enlighten employees on issues of transformation and the management of cultural diversity.

\section{Impact of the management of workplace transformation on productivity}

The results indicate a below average mean score value (mean = 2.40 against a maximum attainable score of five) on the impact of the management of workplace transformation on productivity. It would be expected that if companies were more committed to addressing issues of transformation, employees would be more productive and companies would witness a noticeable turnover. Most companies are more interested in high productivity and profit at the expense of other critical aspects of business. The recognition of employee needs is the most effective way of improving productivity. According to the Institute for Democracy in South Africa (IDASA) (1995), South African companies do not learn from one another's mistakes and successes. According to the study conducted by IDASA, the Sowetan newspaper has come a long way in transforming its racial composition and culture, creating a supportive environment and a cultural space for workers. The Sowetan management has created an environment where very open communication is encouraged. The cultural experience of all employees has been broadened and an atmosphere of tolerance and inclusion is being actively created. Hence, the effective management of cultural diversity is a business imperative and must be prioritised.

\section{SAT Agenda and workplace transformation}

The results (mean $=2.59$ against a maximum attainable score of five) reflect that there is some but insufficient recognition of the relationship between the broad SAT Agenda and what companies are doing in terms of transformation. Though the majority of respondents were from previously disadvantaged groups, senior and strategic positions in all three selected companies were held by white males. Respondents did not believe that there has been a deliberate effort by companies to employ employees from disadvantaged groups to give all South Africa citizens equal opportunities and to reflect the demography of the country. This clearly indicates that although South Africa is a democratic country, democratic principles are not yet the cornerstone of workplace transformation.

\section{Employee involvement in workplace transformation}

The results (mean $=2.36$ against a maximum attainable score of five) reflect that employees play a rather limited role in matters of transformation. The new South African labour legislation, particularly the Employment Equity Act, No. 55 of 1998, compel organisations to involve employees in matters of employment equity. During a personal interview conducted with the chairperson of the trade union from the company in the science and information industry, it was established that while some structures for consultation are in place within the company, the 
involvement of employees and employee representatives has not been recognised. Despite efforts by this company to put in place communication programmes such as transformation sites and newsletters, these tools simply inform employees of what the company is doing regarding its social responsibility and BEE deals but there is no clear communication strategy that actively engages all role-players. Similar experiences were related in South African Breweries' Beer Division and the Development Bank of Southern Africa by IDASA in 1994. As per the results of this survey $(37.4 \%)$, the South African workforce is still subjected to the use of the English language as the medium of communication despite the fact that the South Africa Constitution recognises 11 official languages. This does not suggest that all 11 languages should be used in one company for communication purposes, but with more employee involvement and consultation on issues affecting them, a well-defined communication system will be able to accommodate as many people as possible without creating impenetrable walls caused by communication barriers.

\section{Employment equity legislation}

Since the new democratic dispensation in South Africa, the ANC government has provided legislative frameworks within which South African companies should operate. One of the major strategic objectives was to ensure that like the rest of South African society, companies eradicate discriminatory policies and practices and transform in order to reflect the new democratic dispensation principles that are based on recognition of individual human rights, in practice and in spirit. However, the results of this study reflect that employees do not believe that their companies have done enough to employ and promote previously disadvantaged groups as envisaged in labour legislation, in particular, the Employment Equity Act, No. 55 of 1998 (mean $=2.49$ against a maximum attainable score of five), indicating a serious need for government intervention.

Whilst the majority of companies comply with certain legislative requirements, this is only on paper. Specifically, if one looks at employment equity legislation requirements, one sees that they compel companies to submit employment equity reports on the progress or lack thereof made in the employment and promotion of previously disadvantaged groups in South Africa. All the companies studied have employment equity forums and submit employment equity reports as and when required. However, transformation in terms of their company policies, corporate cultures and the management of cultural diversity has been slow or nonexistent. Thus, transformation has been largely in numbers rather than in totality in all three companies investigated. Although it may be true that no transition is perfect, little is shown by these three companies to indicate efforts through a coherent management strategy to turn around their companies to accommodate different cultural groups, not merely in terms of employing them but also in making sure that they become part of the companies for which they are working through the recognition of their differences as individuals and/ or as cultural groups. Clearly, this indicates a serious limitation and loopholes within the legislation. There is no proper or effective monitoring system to identify companies that do not transform and, as reported in a personal interview by a senior official from the Department of Labour in the Compliance and Monitoring Unit in Pretoria, no cases have been referred to the labour court thus far due to technicalities.

Documentary evidence obtained from the three companies selected for this research indicated that little has changed from pre-1994 human resources policies as envisaged by most of the labour legislation, namely the Employment Equity Act, No. 55 of 1998, the Workplace Skills Development Act, No. 97 of 1998 and the Labour Relations Act, No. 66 of 1995. In a case study conducted on a company in the information and technology industry, it was established that only $2 \%$ of women were part of the executive and directors of the company in 2006. According to Msomi (2006), the South African Women in Corporate Leadership Census shows that the relative representation of women in positions of power does not correspond meaningfully to the proportion of women in the overall working population. Women make up $52 \%$ of the adult population in South Africa and $41 \%$ of the working population but they constitute only $16.7 \%$ of all executive managers in the country. In 2006 a census indicated that $43.4 \%$ of JSE-listed companies do not have women board members at all. Legislation can play a role in facilitating the increase of the number of women on corporate boards. However insufficient support structures, as identified by the study from the three companies, exist to demonstrate commitment. It is clear that the Employment Equity Act, No. 55 of 1998 and other labour legislation have major limitations. They do not provide guidelines or practical steps on how South African companies should go about ensuring that discrimination in the workplace is eradicated.

Is there a need for legislation amendment to compel South African companies to transform?

Whilst the employment rate of South Africans has been relatively impressive over the past few years according to the latest statistics, Peter Vundla (2006), deputy chairman of the investment group AMB Capital and head of the Presidential Black Business Working Group, believes that after 12 years of democracy South Africa has nothing to show in terms of transformation. It is important for an organisation to transform and not just conform as undergoing the transformation process without changing the organisational culture would be indicative of conforming and not transforming. According to Msomi (2006), while various economic indicators continue to show that the country is on the right track, there are few 'social indicators'. The findings of this research indicate that company transformation in general and the management of cultural diversity in particular are being viewed as peripheral issues that matter only when employment equity reports are to be submitted to the Department of Labour and/or when certain government tenders demand certain transformation requirements. Companies in South Africa are not viewing the management of cultural diversity as a corporate governance issue and hence, South Africa cannot afford to leave issues of transformation to the discretion of companies themselves. South Africa, according to Vundla (2006), needs more government intervention, more regulation and more legislation to provide clarity and direction on how to manage cultural diversity in South African companies.

\section{Conclusion}

Evidently, despite worker support for the ANC in the general elections of 1994, 1999, 2004 and 2009, few measures have been put in place to empower, protect and develop employees to take advantage of their constitutional rights of being recognised, firstly, as human beings in the workplace and, secondly, as workers. Although a significant contribution by the ANC-led government has been made through legislative interventions, such legislative interventions have noticeable shortcomings. The fact that even after 15 years of democracy in South Africa one can still find companies whose working environment is very much Eurocentric and undemocratic in nature raises concern. Hence, the recommendations of this study aim to lay a solid foundation towards the realisation of a supportive work environment that appreciates and recognises employees as human beings and assists companies in achieving the broad strategic transformation goals set by the democratically elected government.

\section{Recommendations}

Legislative interventions are necessary to ensure that systems and structures are put in place to advance issues of transformation. To assist companies, the existing employment equity legislation must be amended to ensure the following:Generally accepted transformation standards/principles must be established to provide guidelines on the implementation of workplace transformation and compulsory adherence through legislation must be implemented.

- A Company Transformation Help Centre must be set up 
by the Department of Labour to assist in implementing workplace transformation programmes.

- Transformation committees, representative of the racial, gender and cultural demographics of the country, must be established by all companies as a system or a structure in order to advance the workplace transformation agenda.

- The scope and nature of these transformation committees must be properly defined to include the appointment and duties of independent chairpersons and auditors.

- Mentorship and coaching programmes must be instituted to assist all newly appointed and promoted employees.

- Exit interviews must be compulsory as a method of information gathering.

- Company transformation centres (CTCs) will play some role in training and education. However, companies themselves will still be expected to have a budget set aside for the education and training of employees to enhance the understanding of stakeholders on matters of workplace transformation and the management of cultural diversity and this process will have to be audited.

- Managing workplace transformation has an impact on worker productivity. When companies constantly assess staff satisfaction and motivation, they will be able to develop strategic interventions to proactively manage issues that are threatening to the welfare of staff, the management of cultural programmes and their future stability.

To achieve this end, companies need to do the following:

- Conduct ongoing organisational health surveys in order to establish staff satisfaction, for example with regard to the menu in canteens.

- Constantly review their human resources policies in order to ensure that they are employee centred and sensitive to cultural differences.

- Design and implement BEE schemes to secure a percentage of company ownership in the hands of previously disadvantaged groups to create a sense of belonging and commitment.

- Whilst the SAT Agenda has propelled change in the political and economic spheres, similar developments have not taken place in the South African labour market and, in particular, workplace transformation. Evidently, workplace transformation cannot be left in the hands of companies, but direct government intervention, through legislative amendments, must be initiated in order to ensure that the workers of South Africa are able to take advantage of the new democratic dispensation that they themselves contributed to creating.

In order to ensure an effective employee involvement strategy in workplace transformation, a clear communication strategy must be properly documented and communicated to all role-players and it should incorporate the following:

- Developing a documented communication strategy that will recognise at least three dominant languages in each province

- Establishing consultative structures for engagement between employees and management

- Embarking on annual road shows where companies will make presentations to staff members with regard to progress made on matters of transformation

- Ensuring that trade unions and professional associations play an active role in the communication efforts of companies so that they themselves own the process of improving communication.

\section{Limitations of the study}

This study was limited to employees in three production companies in Gauteng and used questionnaires and personal interviews as methods of data collection. Comparative analyses across different companies, sectors and regions, using a triangulated approach to data collection, may prove to be more beneficial.

\section{Suggestions for further research}

During the course of the research, a number of concerns regarding issues of transformation in the workplace became apparent. Some of these themes were highlighted in the study but require further in-depth research:

- The impact of workplace transformation on young employees

- $\quad$ The role of the education system in educating and preparing the South African youth to work in a multicultural environment

- $\quad$ Establishing employment patterns in order to determine whether all racial and cultural groups are evenly distributed in all categories of employment.

\section{REFERENCES}

Alexander, N. (2006, March). Racial identity, citizenship and nation building in post-apartheid South Africa. Presentation given at University of Fort Hare, East London Campus, South Africa.

Barker, F.S. (1995). The South African labour market: Critical issues for reconstruction. Pretoria: Van Schaik.

Bendix, S. (1996). Industrial relations in South Africa. (3rd edn.). Cape Town: Juta.

Cosatu Policy Unit. (2002). Industrial strategy handbook. South Africa: Braamfontein.

Human, L. (1993). Affirmative action and the development of people: A practical guide. Cape Town: Press Syndicate of the University of Cambridge.

Institute for Democracy in South Africa. (1995). Making affirmative action work - South African guide. Cape Town: Epping.

Kane-Berman, J. (2004, 21 April). The 'transformation' agenda requires alternatives, not consensus. South African Institute of Race Relations - News, p. 1-3.

Moses, B. (2006, 21 May). Glass ceiling not to blame: Women alienated by male corporate culture. City Press.

Msomi, D. (2006, 21 May). Women still under-represented on boards. City Press.

Ngobeni, M. (2006, 28 May). Black job-hopping not all about the money. Sunday Times, Business Times, p. 8.

Ntuli, D. (2006). Do you fit in? Career Junction. Retrieved March 17, 2008, from http://ananzi.careerjunction.co.za

Ramphele, M. (1995). The affirmative action book: Towards an equity environment. Cape Town: IDASA.

Republic of South Africa. (1995). Labour Relations Act, No. 66 of 1995. Pretoria: Government Printers.

Republic of South Africa. (1997). Basic Conditions of Employment Act, No. 75 of 1997. Pretoria: Government Printers.

Republic of South Africa. (1998). Employment Equity Act, No. 55 of 1998. Pretoria: Government Printers.

Republic of South Africa. (1998). Employment Equity Bill. Pretoria: Government Printers.

Republic of South Africa. (1998). Workplace Skills Development Act, No. 97 of 1998. Pretoria: Government Printers.

Richard, O., McMillan-Capehart, A., Chadwick, K., \& Dwyer, S. (2003). When race matters: Exploring key contingencies of the racial diversity-firm performance relationship. Group and Organization Management, 28(1), 107-127.

Sekaran, U. (2003). Research methods for business: A skill-building approach. New York: John Wiley and Sons, Inc.

Terblanche, S. (2002). A history of inequality in South Africa, 16522002. Pietermaritzburg: University of Natal Press.

Thomas, A., \& Robertshaw, D. (1999). Achieving Employment Equity. Randburg: Knowledge Resources (Pty) Ltd.

Vundla, P. (2006, May 10). The Vundla Code. Sunday Times.

Wilken, S. (2003). Affirmative action seen through a court's eyes. Sunday Times Career. Retrieved on 1 December 2006 from http://www.suntimes.co.za/2003/08/31/business/ news/news13.asp

Zulu, S. (2001). The Employment Equity Act: The double-edged sword. Durban: University of Durban-Westville. 